\title{
The TRMM 'Day-1' Radar/Radiometer Combined Rain-Profiling Algorithm
}

\author{
By Ziad S. Haddad \\ Jet Propulsion Laboratory, California Institute of Technology, Pasadena CA
}

Eric A. Smith

Florida State University, Tallahassee FL

Christian D. Kummerow

NASA Goddard Space Flight Center, Greenbelt MD

Toshio Iguchi

Communications Research Laboratory, Tokyo, Japan

Michael R. Farrar

Florida State University, Tallahassee FL

Stephen L. Durden, Marcos Alves

Jet Propulsion Laboratory, California Institute of Technology, Pasadena CA

and

William S. Olson

NASA Goddard Space Flight Center, Greenbelt MD

(Manuscript received 10 December 1996, in revised form 24 April 1997)

\begin{abstract}
The Tropical Rainfall Measuring Mission (TRMM)'s 'day-1' combined radar/radiometer algorithm uses a rain-profiling approach which gives as much importance to the measurements of the TRMM satellite's precipitation radar (PR) and the TRMM microwave imager (TMI) as their respective intrinsic ambiguities warrant, which avoids any ad hoc shortcuts that might introduce large biases in the rain estimates, yet which is simple enough to be operational when TRMM is launched in 1997. The algorithm is based on the idea of estimating the rain profile using the radar reflectivities, while constraining this inversion to be consistent with the radiometer-derived estimate of the total attenuation. To perform the data fusion, the problem is expressed in terms of drop-size-distribution variables. Starting with an a priori probability density function (pdf) for these variables, a Bayesian approach is used to condition the pdf successively on the radar and the radiometer measurements. The resulting algorithm is mathematically consistent and physically reasonable. The conditional variances which it calculates serve to quantify the accuracy of its estimates: small variances indicate that the TRMM observations can indeed be explained by the models used; large variances imply that the models are not sufficiently consistent with the measurements.
\end{abstract}

(C)1997, Meteorological Society of Japan 


\section{Introduction}

"Combined" rain-estimation algorithms represent a new generation of rainfall retrieval schemes that use measurements obtained from different instruments to improve on single-instrument retrieval algorithms. In the case of the Tropical Rainfall Measuring Mission (TRMM, see Simpson et al., 1988), the instruments on the TRMM spacecraft include a precipitation radar ( $\mathrm{PR}$, see Kawanishi et al., 1993), an SSM/I-like passive microwave radiometer (TMI, see Kummerow et al., 1997), an AVHRRlike optical-infrared radiometer, a lightning detection system, and a cloud-radiation budget radiometer. Of these, only the measurements of the PR and those of the TMI are used in the first-generation (or 'day-1') combined algorithm: indeed, these two are the only TRMM instruments which can explicitly detect rain signatures over a meaningful dynamic range, and for which one has well-tested singleinstrument retrieval models that are largely devoid of empiricism. Conversely, the fine resolution of the radar measurements is expected to compensate for the corresponding ambiguity in the radiometer measurements (e.g. in detecting the freezing level), while the robustness of the radiometer measurements should reduce the error which the radar can make when estimating integrated quantities (errors that are due mostly to the significant dependence of the radar backscatter on hydrometeor size).

The TRMM day-1 combined radar/radiometer algorithm follows three guiding principles: the approach must give as much importance to the measurements of the PR and of the TMI as their respective intrinsic ambiguities warrant; any ad hoc shortcuts that might introduce large biases in the rain estimates must be avoided; finally, the approach must remain simple enough for the algorithm to be operational when TRMM is launched in 1997. The algorithm itself is based on the idea, advocated some time ago by J. Weinman et al. (1990), of estimating the "high resolution" rain profile using the spatially detailed radar reflectivities, while constraining this estimation to be consistent with the (independent) estimate of the total attenuation, derived from the passively-measured $10.7-\mathrm{GHz}$ brightness temperature. To account for this constraint as much as the uncertainty (or lack thereof) in the PR and TMI measurements warrants, the problem is expressed in terms of drop-size-distribution (DSD) variables, similar to the expressions which H. Kumagai had proposed earlier for a similar purpose $(\mathrm{Ku}-$ magai et al., 1993). Three mutually independent DSD parameters are used: a bulk quantity parameter $R$ (the rain rate), and two shape parameters $D^{\prime \prime}$ and $s^{\prime \prime}$, the first representing essentially the massweighted mean drop diameter and the second representing essentially the relative standard deviation of diameters about this mean ("essentially" because these variables have to be modified in order to be mutually independent - Eqs. (1)-(3) below relate these parameters to C. Ulbrich's $\mathcal{N} D^{\mu} e^{-\Lambda D}$, (see Ulbrich, 1983). This parameterization was derived from a careful analysis of over 15,000 DSD samples measured during two rainy seasons at Darwin, and during the TOGA-COARE field campaign (Haddad et al., 1997). It produces $Z-R$ and $k-R$ relations $Z=a\left(s^{\prime \prime}, D^{\prime \prime}\right) R^{b\left(s^{\prime \prime}, D^{\prime \prime}\right)}, k=\alpha\left(s^{\prime \prime}, D^{\prime \prime}\right) R^{\beta\left(s^{\prime \prime}, D^{\prime \prime}\right)}$, whose coefficients $a, b, \alpha$, and $\beta$ are completely determined by $s^{\prime \prime}$ and $D^{\prime \prime}$ using a simple look-up table (see Table 1). The fact that $s^{\prime \prime}$ and $D^{\prime \prime}$ are completely independent of $R$ is crucial for two reasons: one may then assume that $s^{\prime \prime}$ and/or $D^{\prime \prime}$ are constant even though the retrieved $R$ will vary; and one can be sure that the $Z-R$ and $k-R$ relations do not hide any implicit dependences on the variables at hand. Ulbrich's DSD parameters can be obtained from $s^{\prime \prime}, D^{\prime \prime}$ and the rainrate profile $R$ using the formulas

$$
\begin{aligned}
\mu & =\frac{1}{s^{\prime \prime 2} D^{\prime \prime 0.23} R^{0.074}}-4 \\
\Lambda & =\frac{1}{s^{\prime \prime 2} D^{\prime \prime 1.33} R^{0.23}} \\
\text { and } \mathcal{N} & =55 \frac{\Lambda^{\mu+4}}{\left.\Gamma(\mu+4)(1-0.53 / \Lambda)^{-\mu-4}\right)} R,
\end{aligned}
$$

with $\mathcal{N} D^{\mu} e^{-\Lambda D} d D$ in $\mathrm{m}^{-3}, D$ in $\mathrm{mm}$, and $R$ in $\mathrm{mm} \mathrm{h}^{-1}$. Since $R$ varies with altitude, these parameters, too, will vary in altitude.

Starting with an a priori probability density function (pdf) for the variables $s^{\prime \prime}, D^{\prime \prime}$ and $R$, a Bayesian approach is used to condition the pdf successively on the radar and the radiometer measurements. Section 2 outlines how the day- 1 algorithm implements this approach. Section 3, 4 and 5 describe the details of the main elements of the algorithm. A test example is described in Section 6. Finally, the plan to validate the algorithm is outlined in Section 7 .

\section{Algorithm Outline}

The problem is the following:

One has profiles of measured radar reflectivities represented by the vectors

$$
\vec{Z}_{n}
$$

(the components of each vector are the reflectivities from the various range bins, and the index $n$ refers to the $n^{\text {th }}$ radar beam), along with radar-derived surface-reference estimates of the one-way path-integrated attenuations

$$
A_{n}
$$

in each of $N$ radar beams constituting a radiometer beam (so $n=1, \cdots, N$ ), and 
Table 1: $a\left(D^{\prime \prime}\right), b\left(D^{\prime \prime}\right), \alpha\left(D^{\prime \prime}\right)$ and $\beta\left(D^{\prime \prime}\right)$, when $s^{\prime \prime}=0.39$

\begin{tabular}{|c||c|c|c|c|c|c|c|c|c|c|c|c|}
\hline$D^{\prime \prime}$ & 0.7 & 0.8 & 0.9 & 1.0 & 1.1 & 1.2 & 1.3 & 1.4 & 1.5 & 1.6 & 1.7 & 1.8 \\
\hline$a$ & 73.34 & 99.6 & 137.77 & 192.73 & 268.6 & 372.48 & 506 & 675 & 880.36 & 1128.56 & 1404 & 1719.5 \\
\hline$b$ & 1.45 & 1.49 & 1.503 & 1.501 & 1.487 & 1.466 & 1.439 & 1.41 & 1.378 & 1.345 & 1.314 & 1.282 \\
\hline$\alpha$ & 0.0168 & 0.0181 & 0.02 & 0.0225 & 0.0254 & 0.0283 & 0.0313 & 0.0343 & 0.0372 & 0.0401 & 0.0428 & 0.0455 \\
\hline$\beta$ & 1.138 & 1.155 & 1.159 & 1.154 & 1.144 & 1.133 & 1.122 & 1.11 & 1.1 & 1.087 & 1.076 & 1.064 \\
\hline
\end{tabular}

an associated 10.7 GHz brightness temperature

$$
T \text {. }
$$

From these measurements, it is required to estimate the rain rate profiles

$$
\vec{R}_{n}
$$

(again, the components of each vector are the rain rates at the various range bins, and the index $n$ refers to the $n^{\text {th }}$ radar beam), the

shape parameters of the associated DSD and the

uncertainty in $R$ and the DSD shape parameters,

assuming that the DSD shape parameters $\left(D^{\prime \prime}, s^{\prime \prime}\right)$ are uniform in altitude and within the radiometer beam (as was pointed out in the previous section, this uniformity assumption will not apply to the resulting $\Lambda$, $\mu, \mathcal{N}$, which will be expected to vary from range bin to range bin and from one radar beam to another).

The simplifying assumptions about the variability of $\left(s^{\prime \prime}, D^{\prime \prime}\right)$ have to be made in order to reduce the computational requirements of the algorithm. Since the analysis of the Darwin and TOGA-COARE DSD measurements (see Haddad et al., 1997) shows that $s^{\prime \prime}$ does not vary much about its means, it is not unreasonable to assume that it is always equal to its empirical mean $s^{\prime \prime}=0.39$ with probability 1 . Also, since $D^{\prime \prime}$ remains approximately constant over several kilometers (Haddad et al., 1997), the simplifying assumption that it is constant over any given radiometer footprint is also reasonable. With these assumptions, and given a radar inversion algorithm and a radiometer forward model, the sequence of steps taken by the Day-1 combined algorithm is:

0) The "outer shell" — co-locating TMI with PR: sequentially input sets of 4 contiguous raw 10.7$\mathrm{GHz}$ TMI measurements (see Fig. 1). Identify the $N$ radar beams included in the union of these footprints ("inclusion" of a radar beam within a TMI footprint is determined by the value of the TMI beam pattern function in the direction of the radar beam in question - in practice $N \simeq(1+7+1) \times(2+12+2)=144)$. 1a) Input the $\vec{Z}_{n}$ measured in the $n^{\text {th }}$ radar beam $(n=1, \cdots, N)$, along with the additional parameters that the TRMM radar-only profiling algorithm uses, namely the radar-derived surface-reference estimates of the total oneway path attenuation $A_{n}$, and the type of rain within the radar beam.

1b) For every value of the DSD shape parameter $D^{\prime \prime}$ whose a priori probability $\operatorname{pr}\left(D^{\prime \prime}\right)$ is non-zero, run a slightly modified version of the radaronly inversion algorithm and store its intermediate estimated rain profiles $\tilde{R}_{n}\left(D^{\prime \prime}\right)$ and its estimates of the integrated one-way attenuations $\kappa_{n}\left(D^{\prime \prime}\right)$.

2) When all values of $D^{\prime \prime}$ have been considered on all the radar beams, combine the corresponding attenuation estimates $\kappa_{n}\left(D^{\prime \prime}\right)$ to form the corresponding predicted brightness temperatures $t_{i}\left(D^{\prime \prime}\right)(i=1, \cdots, 4)$ within the four TMI footprints, using the radiometer forward model and the value of the TMI antenna pattern at each radar beam with respect to the relevant TMI footprint.

3) Quantify with conditional probabilities the degree to which the $\left(t_{1}, \cdots, t_{4}\right)$ predicted by different $D^{\prime \prime}$ 's match the $\left(T_{1}, \cdots, T_{4}\right)$ measured in the 4 TMI footprints. The average of $D^{\prime \prime}$ for the 4 TMI fields of view. The uncertainty in this estimate is given by the variance of the probability.

4) Go back to the individual radar beams within the intersection of the four TMI footprints, and for each one calculate the average (over $D^{\prime \prime}$ ) of $\tilde{R}_{n}$ weighted by the probability computed in 3 ), and its variance. Here $n=1, \cdots, N^{\prime}$, with $N^{\prime}<$ $N$ (in practice, $N^{\prime} \simeq 7 \times 12=84$ ). Similarly compute the average of the attenuation $\kappa_{n}$.

5) Output, for each individual radar beam within the intersection of the four TMI footprints, the estimated rain rate profile and its r.m.s. error as calculated in Step 4, the estimated value of $D^{\prime \prime}$, the estimated value of the integrated attenuation and its r.m.s. error as calculated in Step 4, and the average of the attenuation derived from the TMI measurement only (using the inverse of the radiometer forward formula). 


\section{Port}

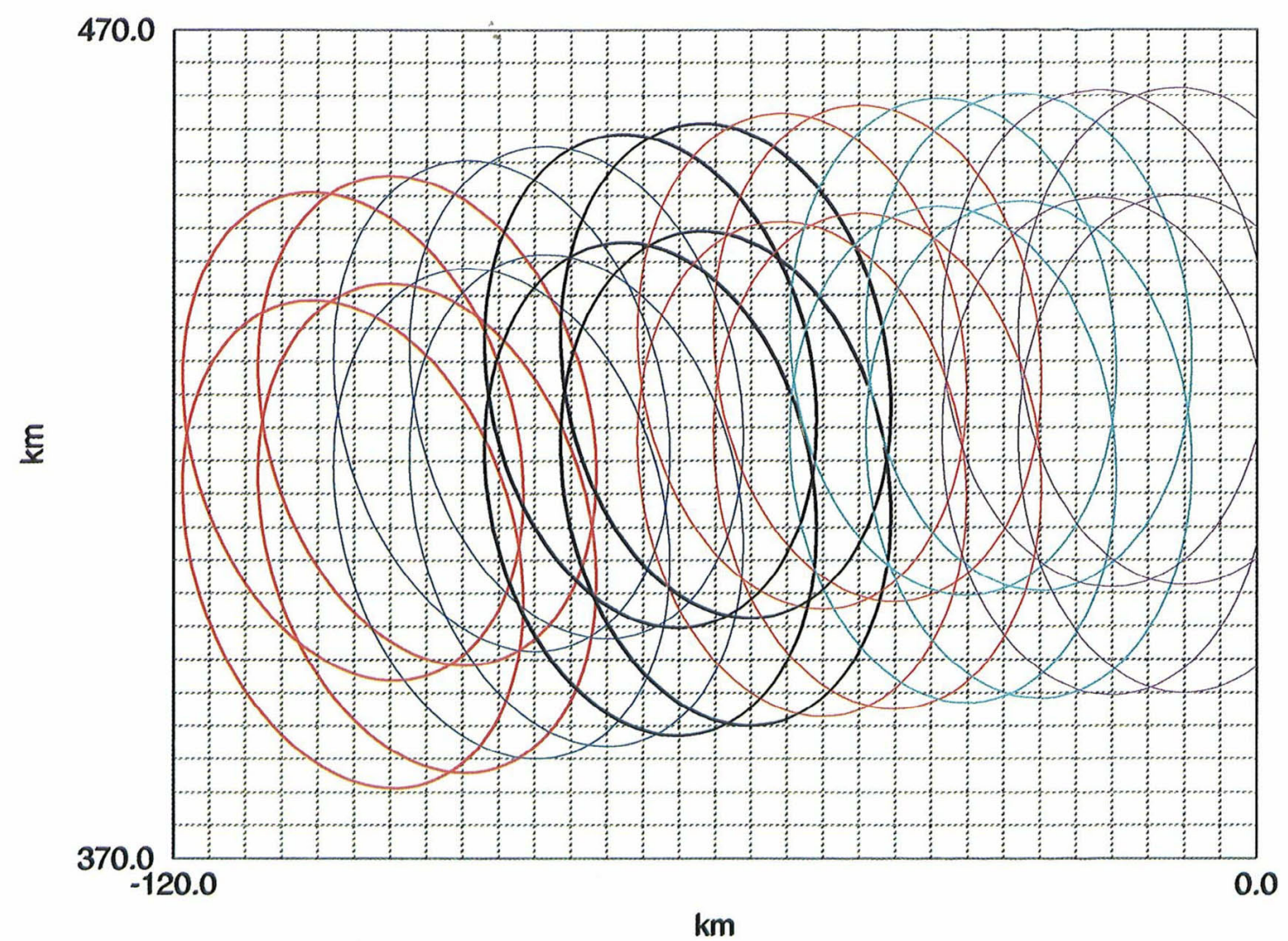

Fig. 1. 12 port-side TMI footprint patterns "within" a PR swath, assuming a 10.7-GHz 3-dB beam that is $36 \mathrm{~km}$ wide and $60 \mathrm{~km}$ tall (see Kummerow et al., 1997) - the $4 \mathrm{~km} \times 4 \mathrm{~km}$ grid gives an idea of the relative size of the radar beams. The satellite track lies along the vertical axis corresponding to the value 0 for the horizontal coordinate.

From these outputs, one can easily evaluate the liquid water content $M$. Indeed,

$$
\begin{aligned}
M & =\rho \int \frac{4}{3} \pi\left(\frac{D}{2}\right)^{3} N(D) d D \\
& \simeq \frac{0.02878 R}{1-(1+0.53 / \Gamma)^{-\mu-4}} \mathrm{~g} \mathrm{~m}^{3},
\end{aligned}
$$

with the density of water $\rho=1 \mathrm{~g} \mathrm{~cm}^{-3}, \mu$ and $\Lambda$ as in (1) and (2) with $s^{\prime \prime}=0.39$.

Section 3 summarizes the physical models giving the radar inversion algorithm and the radiometer forward formula. The details of the co-location procedure are given in Section 4. Section 5 describes how the Bayesian approach was applied to calculate the various conditional probabilities.

\section{The Radiometer and Radar Models}

The radiometer model used in the Day-1 combined algorithm consist of a formula expressing the average 13.8-GHz one-way path-integrated attenua- tion (PIA) $A$, in $\mathrm{dB}$, as a function of the corresponding 10.7-GHz brightness temperature $T_{b}$ :

$$
\tilde{A}\left(T_{b}\right)=c_{0}+c_{1} \log \left(c_{2}-T_{b}\right)
$$

along with a tabulated estimate of the associated r.m.s. uncertainty $\sigma_{0}\left(T_{b}\right)$. The derivation of this formula and the values of the coefficients $\left(c_{0}, c_{1}, c_{2}\right)$ at the various viewing angles and of $\sigma_{0}\left(T_{b}\right)$ required many thousands of radiative transfer calculations. They are described in great detail in Smith et al. (1997). Thus the Day-1 combined algorithm assumes that, over the ocean, given a passive 10.7GHz observed brightness $T_{b}$, the corresponding 13.8$\mathrm{GHz}(\log$-)attenuation is normally distributed with mean $\tilde{A}\left(T_{b}\right)$ and variance $\sigma_{0}\left(T_{b}\right)^{2}$. Since this model is of dubious (if any) value over land, the variance $\sigma_{0}\left(T_{b}\right)^{2}$ is artificially increased in these cases to render the radiometer model's predictions irrelevant and the Day-1 combined algorithm then relies entirely on the radar inversion to estimate the rain.

The radar inversion model is an adapted version of the deterministic TRMM 'day-1' radar-only al- 
gorithm. This eliminates any discrepancies between the estimates of the combined algorithm and those of the TRMM radar-only algorithm which could be attributed to differences in the radar inversion models. When the radar-only estimate of the PIA is deemed useable by the radar-only algorithm, the "surfacereference technique" (Marzoug and Amayenc, 1991) is used to estimate the average rain-rate $r$ at range $x$ :

$$
\begin{aligned}
& \left.r\left(D^{\prime \prime}, Z, A\right)\right|_{x} \\
& =\frac{Z(x)^{1 / b}}{\left(\left(a 10^{-0.2 A}\right)^{\beta / b}+\frac{0.21 \log (10) \alpha \beta}{b} \int_{x}^{x_{s}} Z^{\beta / b}\right)^{1 / \beta}},
\end{aligned}
$$

in which $Z$ denotes the radar reflectivities, $A$ denotes the measured PIA in $\mathrm{dB}, x_{s}$ is the surface range, and $a=a\left(D^{\prime \prime}\right), b=b\left(D^{\prime \prime}\right) \alpha=\alpha\left(D^{\prime \prime}\right)$ and $\beta=\beta\left(D^{\prime \prime}\right)$ are the coefficients of the $Z-R$ and $k-R$ relations, $Z=a R^{b}, k=\alpha R^{\beta}$, derived in Haddad et al. (1997) as a function of the DSD parameters $s^{\prime \prime}$ and $D^{\prime \prime}$ (for the Day-1 combined algorithm, $s^{\prime \prime}$ is assumed constant $=0.39$ ). When the surface-reference information is not useable, the direct Hitschfeld-Bordan formula (Hitschfeld and Bordan, 1954)

$$
\left.r\left(D^{\prime \prime}, Z, A\right)\right|_{x}=\frac{Z(x)^{1 / b}}{\left(a^{\beta / b}-\frac{0.21 \log (10) \alpha \beta}{b} \int_{0}^{x_{s}} Z^{\beta / b}\right)^{1 / \beta}}
$$

is used instead (range 0 is assumed to represent the storm top). In cases where a bright-band is detected by the radar, the $Z-R$ and $k-R$ coefficients given above are used only for the portion of the profile that falls below the bright band; for the higher altitudes, the pre-determined bright-band and ice coefficients that are used in the TRMM radar-only algorithm will also be used by the Day-1 combined algorithm.

Thus, the radar model can always turn a reflectivity profile $Z$ into a rain-rate profile $r$, over land as well as over the ocean. Finally, given the estimated rain profiles $r_{n}$ in $N$ contiguous radar beams constituting one $10.7-\mathrm{GHz}$ radiometer beam, and given a value for the DSD shape parameter $D^{\prime \prime}$, the two models above can predict the brightness temperature that should be observed within the radiometer beam. Indeed, the radar model can calculate the attenuations $\kappa_{n}\left(D^{\prime \prime}\right)\left(=\int_{0}^{x_{s}} \alpha r\left(D^{\prime \prime}, Z, A\right)^{\beta}\right)$ within each radar beam, and the predicted brightness temperature $t\left(r_{1}, \cdot, r_{N} ; D^{\prime \prime}\right)$ is therefore the antennapattern weighted sum

$$
t\left(r_{1}, \cdots, r_{N} ; D^{\prime \prime}\right)=c_{2}-\sum_{n=1}^{N} w_{n} e^{\left(\kappa_{n}\left(D^{\prime \prime}\right)-c_{0}\right) / c_{1}}
$$

in which $w_{n}$ denotes the value of the antennapattern weight for the $n^{\text {th }}$ radar beam, with $\sum w_{n}=$ 1 .

\section{The Co-Registration Problem}

Combining the measurements of two different instruments requires that one be able to situate the field of view (FOV) of one instrument with respect to the other. Before attempting to solve this "coregistration" problem, one must first assume that the volume within the intersection of the two instruments' fields of view was probed at the same time by the two instruments. in our case, because the radiometer does not scan from a nadir attitude but rather with $\mathrm{a} \simeq 50^{\circ}$ incidence angle, there will typically be $\mathrm{a} \simeq 1$ minute difference between the times at which a given rain volume is observed by the radar and the radiometer. The Day- 1 algorithm makes no attempt to take this lag into account.

As to the co-registration problem, in our case, the radar and radiometer fields of view do not have sharp boundaries: in fact the FOVs are determined by the respective antenna beam patterns, which then act as weighting functions and allow one some latitude in defining the "intersection" of a particular radiometer footprint with a given radar scan, the "inclusion" of one radar reflectivity profile in a given radiometer beam, etc... The Day-1 algorithm handles the problem by first reading the coordinates of all the beams within every radar scan of the data "granule" that is being processed (generically, a data granule covers one TRMM orbit). For every radar scan, whose center has longitude $L_{0}$ and latitude $l_{0}$, say, the algorithm calculates the scaling constant $r$ and rotation angle $\theta$ which allow one to transform a longitude-latitude pair $(L, l)$ into locally cartesian coordinates $(x, y)$,

$$
\left(\begin{array}{l}
x \\
y
\end{array}\right)=r\left(\begin{array}{cc}
\sin (\theta) & -\cos (\theta) \\
\cos (\theta) & \sin (\theta)
\end{array}\right)\left(\begin{array}{c}
r_{0} \cos \left(l_{0}\right)\left(L-L_{0}\right) \\
r_{0}\left(l-l_{0}\right)
\end{array}\right)
$$

in which the positive $y$ direction is the TRMM direction of motion (in (9), $r_{0}$ is the radius of the earth, $r$ is determined so the individual adjacent beam center spacings are closest to the theoretical pattern, and $\theta$ is determined so the scan is as close to the $x$-axis as possible $-\theta$ is essentially the angle between the local latitude and the TRMM track). Local distances near the given radar scan are (quite adequately) approximated by $\left(\Delta x^{2}+\Delta y^{2}\right)^{1 / 2}$.

Having stored the coordinate change parameters $(r, \theta)$ for each radar scan as in $(9)$, the day-1 algorithm next identifies those TMI footprints which fall within the radar swath, and which will be processed as outlined in Section 1. For each radar beam, it finds the closest TMI footprint, then, within that footprint's TMI scan, it finds the second closest TMI footprint. The number of times that each TMI beam is selected is stored, and, when all radar beams have been thus examined, the 24 "most popular" TMI beams within each TMI scan (i.e. those selected 
most often) are identified, and are grouped into adjacent non-overlapping quadruples for further processing (see Fig. 1).

Once the TMI FOV-quadruples have been identified, every radar beam is associated to the quadruple closest to it, and the radar beam is identified as within the "intersection" of the four FOVs in question: when the latter are processed as outlined in Section 1, the rain estimates for the radar beams within its intersection will be output. Finally, the radar beams within the "union" of the FOVs forming every TMI quadruple are identified: when the latter are processed, the radar reflectivities for the radar beams within the union will be input.

Thus, every radar beam is included in the "intersection" (hence output) of exactly one quadruple of TMI footprints. And all the radar beams affecting the predictions within the union of every TMI quadruple are taken into account (i.e. input to the Bayesian algorithm). Finally, the value of the antenna beam pattern weight of a given radar beam is zeroed when the "bad data" or "no rain" flags are raised for the radar beam in question.

\section{Mathematical Details of the Bayesian Ap- proach}

Assume that a radiometer beam encompassing $N$ radar beam, numbered $n=1, \cdots, N$, is given. The problem is to determine the function

$$
\mathcal{P}\left(D^{\prime \prime},\left(\vec{R}_{1}, \epsilon_{1}\right), \cdots,\left(\vec{R}_{N}, \epsilon_{N}\right)\right)
$$

expressing the conditional probability of having $D^{\prime \prime}$ as the DSD shape parameter throughout the radiometer beam, $\vec{R}_{n}$ as the rain rate vector for the $n^{\text {th }}$ radar beam (a vector whose components are the rain rates at the binned altitudes), and $\epsilon_{n}$ as the product of the correction to the radar calibration constant in that beam, times the correction to the surface backscattering coefficient within that beam (corrections that are imposed by the radar "surface reference technique"). This probability is conditional in the sense that it is assumed to have accounted for the following observations:

- the radar reflectivities $\vec{Z}_{n}$ within the $n^{\text {th }}$ beam,

- the one-way integrated attenuations $A_{n}$ obtained from the measurement of the surface cross-section within that beam,

- and the brightness temperature $T$.

Bayes's theorem can help rewrite $\mathcal{P}$ in a form which makes it easier to calculate:

$$
\begin{aligned}
& \mathcal{P}\left(D^{\prime \prime},\left(\vec{R}_{1}, \epsilon_{1}\right), \cdots,\left(\vec{R}_{N}, \epsilon_{N}\right)\right) \\
& \quad=\operatorname{pr}\left(D^{\prime \prime},\left(\vec{R}_{1}, \epsilon_{1}\right), \cdots,\left(\vec{R}_{N}, \epsilon_{N}\right) \mid\right.
\end{aligned}
$$

$$
\begin{aligned}
&\left.T,\left(\vec{Z}_{1}, A_{1}\right), \cdots,\left(\vec{Z}_{N}, A_{N}\right)\right) \\
&= \operatorname{pr}\left(T \mid D^{\prime \prime},\left(\vec{R}_{1}, \epsilon_{1}\right), \cdots,\left(\vec{R}_{N}, \epsilon_{N}\right),\right. \\
&\left.\left(\vec{Z}_{1}, A_{1}\right), \cdots,\left(\vec{Z}_{N}, A_{N}\right)\right) \\
& \cdot \operatorname{pr}\left(D^{\prime \prime},\left(\vec{R}_{1}, \epsilon_{1}\right), \cdots,\left(\vec{R}_{N}, \epsilon_{N}\right) \mid\right. \\
&\left.\left(\vec{Z}_{1}, A_{1}\right), \cdots,\left(\vec{Z}_{N}, A_{N}\right)\right) \\
& \cdot \operatorname{pr}\left(T \mid\left(\vec{Z}_{1}, A_{1}\right), \cdots,\left(\vec{Z}_{N}, A_{N}\right)\right)^{-1}
\end{aligned}
$$

The last term is a constant as far as the variables $\left\{D^{\prime \prime},\left(\vec{R}_{n}, \epsilon_{n}\right)\right\}$ are concerned. Call it $\mathcal{C}$. Using $(5)$ and (8), Eq. (10) becomes

$$
\begin{aligned}
\mathcal{P} & \left(D^{\prime \prime},\left(\vec{R}_{1}, \epsilon_{1}\right), \cdots,\left(\vec{R}_{N}, \epsilon_{N}\right)\right) \\
= & \mathcal{G}_{\sigma 0(T)}\left(\tilde{A}(T)-\tilde{A}\left(t\left(\vec{R}_{1}, \cdots, \vec{R}_{N} ; D^{\prime \prime}\right)\right)\right) \\
& \cdot \operatorname{pr}\left(D^{\prime \prime},\left(\vec{R}_{1}, \epsilon_{1}\right), \cdots,\left(\vec{R}_{N}, \epsilon_{1}\right) \mid\right. \\
& \left.\left(\vec{Z}_{1}, A_{1}\right), \cdots,\left(\vec{Z}_{N}, A_{N}\right)\right) \cdot \mathcal{C}
\end{aligned}
$$

where the notation " $\mathcal{G}_{\sigma}$ " refers to the 0-mean Gaussian density function with variance $\sigma^{2}$. The middle term in the right-hand-side of (11) can be further simplified using Bayes's theorem again:

$$
\begin{aligned}
\operatorname{pr} & \left(D^{\prime \prime},\left(\vec{R}_{1}, \epsilon_{1}\right), \cdots,\left(\vec{R}_{N}, \epsilon_{N}\right) \mid\right. \\
& \left.\left(\vec{Z}_{1}, A_{1}\right), \cdots,\left(\vec{Z}_{N}, A_{N}\right)\right) \\
= & \operatorname{pr}\left(\left(\vec{R}_{1}, \epsilon_{1}\right), \cdots,\left(\vec{R}_{N}, \epsilon_{N}\right) \mid\right. \\
& \left.D^{\prime \prime},\left(\vec{Z}_{1}, A_{1}\right), \cdots,\left(\vec{Z}_{N}, A_{N}\right)\right) \\
\cdot & \operatorname{pr}\left(D^{\prime \prime} \mid\left(\vec{Z}_{1}, A_{1}\right), \cdots,\left(\vec{Z}_{N}, A_{N}\right)\right)
\end{aligned}
$$

which, if beam-to-beam independence is assumed and if the radar model of the previous section is used, becomes

$$
\begin{aligned}
\operatorname{pr} & \left.\left(D^{\prime \prime},\left(\vec{R}_{1}, \epsilon_{1}\right), \cdots,\left(\vec{R}_{N}, \epsilon_{N}\right) \mid\left(\vec{Z}_{1}, A_{1}\right), \cdots, A_{N}\right)\right) \\
= & {\left[\prod_{n=1}^{N} \operatorname{pr}\left(\vec{R}_{n}, \epsilon_{n} \mid D^{\prime \prime}, \vec{Z}_{n}, A_{n}\right)\right] } \\
& \cdot \operatorname{pr}\left(D^{\prime \prime} \mid\left(\vec{Z}_{1}, A_{1}\right), \cdots,\left(\vec{Z}_{N}, A_{N}\right)\right) \\
\simeq & {\left[\prod_{n=1}^{N} \delta\left(\vec{R}_{n}-r\left(D^{\prime \prime}, \vec{Z}_{n}, A_{n}+\epsilon_{n}\right)\right)\right.} \\
& \left.\cdot \delta\left(\epsilon_{n}-e\left(D^{\prime \prime}, \vec{Z}_{n}, A_{n}\right)\right) \cdot \mathcal{G}_{\sigma_{n}}\left(e\left(D^{\prime \prime}, \vec{Z}_{n}, A_{n}\right)\right)\right] \\
& \cdot \operatorname{pr}\left(D^{\prime \prime}\right)
\end{aligned}
$$

where " $\delta$ " is the Dirac $\delta$-function, and the function $r$ represents the rain-rate profile obtained from the reflectivity profile using the radar inversion, as in (6), (7). In addition, to obtain (14) it was assumed that, given $k-R$ and $Z-R$ coefficients as well as the surface cross-sections, one can directly determine from 
the vector $\vec{R}$ the correction $\epsilon$ that must be made to the PIA estimated by reference to the surface (assuming one has an a priori estimate of the surface back-scattering cross-section), using a deterministic formula represented by the function $e$. In fact, (6) and (7) imply that (see Haddad et al., 1995)

$$
\begin{aligned}
& e\left(D^{\prime \prime}, \vec{Z}, A\right)=\frac{10 b\left(D^{\prime \prime}\right)}{\beta\left(D^{\prime \prime}\right)} \\
& \times \log _{10}\left(1-\frac{0.21 \log (10) \alpha\left(D^{\prime \prime}\right) \beta\left(D^{\prime \prime}\right)}{b\left(D^{\prime \prime}\right)}\right. \\
& \left.\quad \times \int_{0}^{r_{s}}\left(\frac{Z}{a\left(D^{\prime \prime}\right)}\right)^{\beta\left(D^{\prime \prime}\right) / b\left(D^{\prime \prime}\right)}\right) \\
& -10 \log _{10}(A) .
\end{aligned}
$$

This correction must then fall within the expected uncertainty of the calibration constant and of the a priori estimate of the surface cross-section, represented by $\sigma_{n}$. Finally, the conditional density function of the DSD shape parameter $D^{\prime \prime}$ given the radar observations is assumed to be approximately the same as the a priori (unconditioned) density function of $D^{\prime \prime}$.

Of the terms in (14), only the calculation of the last one has not yet been discussed. The initialization of $\operatorname{pr}\left(D^{\prime \prime}\right)$ is derived from the statistical analyses of the Darwin and TOGA-COARE data sets. Indeed, the latter show that $D^{\prime \prime}$ can be assumed to be lognormal, with somewhat different statistics in stratiform and convective rain. Since the two categories are mutually exclusive, the a priori pdf of $D^{\prime \prime}$ for a given radiometer footprint can be expressed as

$$
\begin{aligned}
\operatorname{pr}\left(D^{\prime \prime}\right)= & \operatorname{pr}\left(D^{\prime \prime} \mid \text { stratiform }\right) \cdot \operatorname{pr}\{\text { stratiform }\} \\
& +\operatorname{pr}\left(D^{\prime \prime} \mid \text { convective }\right) \cdot \operatorname{pr}\{\text { convective }\} \\
& +\operatorname{pr}\left(D^{\prime \prime} \mid \text { unknown }\right) \cdot \operatorname{pr}\{\text { other }\}
\end{aligned}
$$

in which "pr\{stratiform\}" is interpreted as the proportion of radar beams within the given TMI footprint which were classified as "stratiform" by the TRMM "radar-qualitative" algorithm, and "pr\{convective\}" and "pr\{other\}" are interpreted likewise. The first factor in each summand of (16) is given the corresponding value calculated from the Darwin/COARE data (Haddad et al., 1997).

Going back to Eq. (11) and replacing the middle term by (14), one can finally reach the goal of expressing the original conditional density function in the following simple and practical form:

$$
\begin{gathered}
\mathcal{P}\left(D^{\prime \prime},\left(\vec{R}_{1}, \epsilon_{1}\right), \cdots,\left(\vec{R}_{N}, \epsilon_{N}\right)\right) \simeq \mathcal{C} \\
\cdot \mathcal{G}_{\sigma 0(T)}\left(\tilde{A}(T)-\tilde{A}\left(t\left(\vec{R}_{1}, \cdots, \vec{R}_{N} ; D^{\prime \prime}\right)\right)\right) \\
\cdot \delta\left[\prod_{n=1}^{N} \delta\left(\vec{R}_{n}-r\left(D^{\prime \prime}, \vec{Z}_{n}, A_{n}+\epsilon_{n}\right)\right)\right. \\
\cdot\left(\epsilon_{n}-e\left(D^{\prime \prime}, \vec{Z}_{n}, A_{n}\right)\right)
\end{gathered}
$$

$\left.\cdot \mathcal{G}_{\sigma_{n}}\left(e\left(D^{\prime \prime}, \vec{Z}_{n}, A_{n}\right)\right)\right] \cdot \operatorname{pr}\left(D^{\prime \prime}\right)$

where $\mathcal{C}$ is the normalizing constant guaranteeing that the integral of the left-hand-side is one. Note that of the several unknowns at the start, the only independent variable in (17) that is not given by a deterministic expression is $D^{\prime \prime}$. Practically, this means that $\mathcal{P}$ only depends on $D^{\prime \prime}$ (and, naturally, on the observed quantities $\left\{\vec{Z}_{n}, A_{n}\right\}$ and $T$ ).

How can one estimate rain-rate/DSD profiles from the conditional probability? Formula (17) can be used to calculate the first two moments of $\mathcal{P}$. To make the notation more transparent, rename $e\left(D^{\prime \prime}, \vec{Z}_{n}, A_{n}\right), r\left(D^{\prime \prime}, \vec{Z}_{n}, A_{n}+\epsilon_{n}\right)$, and $t\left(\vec{R}_{q}, \cdots, \vec{R}_{N} ; D^{\prime \prime}\right)$ as follows:

$$
\begin{aligned}
\text { Call } \tilde{e}_{n}\left(D^{\prime \prime}\right)= & e\left(D^{\prime \prime}, \vec{Z}_{n}, A_{n}\right), \\
\tilde{R}_{n}\left(D^{\prime \prime}\right)= & r\left(D^{\prime \prime}, \vec{Z}_{n}, A_{n}+\tilde{e}_{n}\left(D^{\prime \prime}\right)\right) \\
& (\text { this is a vector }) \\
\tilde{t}\left(D^{\prime \prime}\right)= & t\left(\tilde{R}_{1}\left(D^{\prime \prime}\right), \cdots, \tilde{R}_{N}\left(D^{\prime \prime}\right) ; D^{\prime \prime}\right),
\end{aligned}
$$

and

$$
\begin{aligned}
K\left(D^{\prime \prime}\right)= & \mathcal{G}_{\sigma 0(T)}\left(\tilde{A}(T)-\tilde{A}\left(\tilde{t}\left(D^{\prime \prime}\right)\right)\right) \\
& \cdot\left(\prod_{n=1}^{N} \mathcal{G}_{\sigma n}\left(\tilde{e}_{n}\left(D^{\prime \prime}\right)\right)\right) \cdot \operatorname{pr}\left(D^{\prime \prime}\right) .
\end{aligned}
$$

This notation brings out the dependence of the variables to be estimated on the parameter $D^{\prime \prime}$ (and while the dependence on the observations $\left\{\vec{Z}_{n}\right\}$, $\left\{A_{n}\right\}$ and $T$ is no longer explicitly evident, this helps unclutter the formulas that follow). The first moments of $\mathcal{P}$ give the estimates $\hat{D}, \hat{R}_{m}$, and $\hat{\epsilon}_{m}$, of the variables $D^{\prime \prime}, \vec{R}_{m}$, and $\epsilon_{m}$ (with $\left.m=1, \cdots, N\right)$, given the observations $\vec{Z}_{n}, A_{n}$ (with $n=1, \cdots, N$ ) and $T$, namely

$$
\begin{aligned}
\hat{D} & =\mathcal{C} \cdot \int D^{\prime \prime} \cdot K\left(D^{\prime \prime}\right) d D^{\prime \prime} \\
\hat{\epsilon}_{m} & =\mathcal{C} \cdot \int \tilde{e}_{m}\left(D^{\prime \prime}\right) \cdot K\left(D^{\prime \prime}\right) d D^{\prime \prime} \\
\hat{R}_{m} & =\mathcal{C} \cdot \int \tilde{R}_{m}\left(D^{\prime \prime}\right) \cdot K\left(D^{\prime \prime}\right) d D^{\prime \prime}
\end{aligned}
$$

where $\mathcal{C}=\left(\int K\left(D^{\prime \prime}\right) d D^{\prime \prime}\right)^{-1}$. The uncertainties in these estimates are given by

$$
\begin{aligned}
\sigma\left(D^{\prime \prime}\right)^{2} & =-\hat{D}^{2}+\mathcal{C} \cdot \int D^{\prime \prime 2} \cdot K\left(D^{\prime \prime}\right) d D^{\prime \prime} \\
\sigma\left(\epsilon_{m}\right)^{2} & =-\hat{\epsilon}_{m}^{2}+\mathcal{C} \cdot \int \tilde{e}_{m}\left(D^{\prime \prime}\right)^{2} \cdot K\left(D^{\prime \prime}\right) d D^{\prime \prime} \\
\sigma\left(R_{m, i}\right)^{2} & =-\hat{R}_{m, i}^{2}+\mathcal{C} \cdot \int \tilde{R}_{m}\left(D^{\prime \prime}\right)_{i}^{2} \cdot K\left(D^{\prime \prime}\right) d D^{\prime \prime}
\end{aligned}
$$

where $R_{m, i}$ is the rain rate in the $m^{\text {th }}$ radar beam at the $i^{t h}$ range bin, $\hat{R}_{m, i}$ is the $i^{t h}$ component of $\hat{R}_{m}$, and $\tilde{R}_{m}\left(D^{\prime \prime}\right)_{i}$ is the $i^{\text {th }}$ component of $\tilde{R}_{m}\left(D^{\prime \prime}\right)$. 
$2 a$

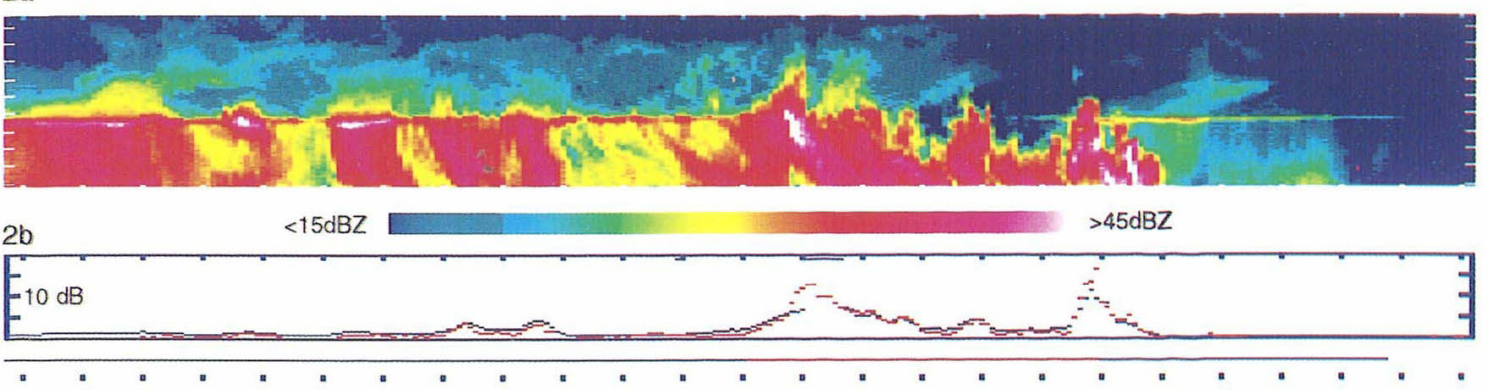

Fig. 2. ARMAR data from T.C. Oliver during the TOGA-GOARE campaign: (a) vertical section of the 13.8-GHz radar reflectivities - the horizontal tick marks are spaced $5=\mathrm{km}$ apart, the vertical ones $1 \mathrm{~km}$ apart starting $1 \mathrm{~km}$ above mean sea level; (b) graphs of the one-way attenuation corresponding to the measured 13.8-GHz brightness temperature (blue), of the radar-surface-reference-derived one way attenuation (red), and of the ad hoc convective(red)/stratiform(blue) classification - the vertical tick marks are spaced $5 \mathrm{~dB}$ apart.

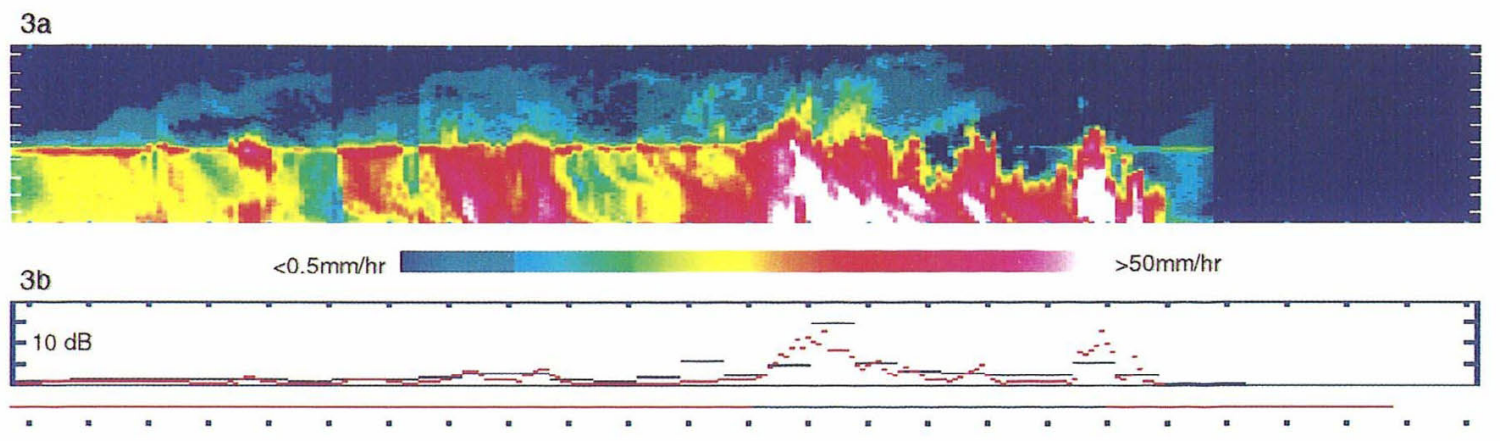

Fig. 3. Combined-algorithm estimate of the rain field corresponding to the data of Fig. 2: (a) the rain rate (in $\mathrm{dBR}=10 \log _{10}\left(\mathrm{~mm} \mathrm{~h}^{-1}\right)$ ); (b) graphs of the one-way attenuation corresponding to the synthesized brightness tempcrature (blue), of the algorithm-estimated one way attenuation (red), and of the ad hoc convective(blue)/stratiform(red) classification - the vertical tick marks are spaced $5 \mathrm{~dB}$ apart.

In effect, for each value of $D^{\prime \prime}$ the surfacereference-derived integrated attenuations $A_{n}$ in the various radar beam are corrected by $e\left(D^{\prime \prime}\right)$ to make them consistent with the radar-rain relations imposed by that value of $D^{\prime \prime}$, and these corrected attenuations are subsequently compared to the radiometer-derived attenuations to select that value of $D^{\prime \prime}$ which produces the best match, i.e. the mean of (17).

\section{An Example}

Figure 2 shows a vertical section of the atmosphere along the track of the airborne ARMAR radar (Durden et al., 1994) during one of its overflights of a meso-scale system on February 6, 1993, during the TOGA-COARE campaign: Figure 2a displays the radar reflectivities, while Figure $2 \mathrm{~b}$ shows graphs of the one-way attenuation corresponding to the passively-measured $13.8 \mathrm{GHz}$ radiance, the one-way attenuation derived by referencing the reflectivity to the clear-air average surface reflectivity, and the (ad hoc) convective/stratiform "classification". These data were processed using a simplified two-dimensional version of the TRMM day-1 combined algorithm. Since the ARMAR radar and radiometer beams share the same field of view (corresponding to an approximately circular footprint of about $450 \mathrm{~m}$ diameter), average brightness temperatures corresponding to a ten-times larger passive antenna were synthesized. Figure 3 shows the estimates of the adapted 'combined' algorithm. The effect of the brightness temperature on the estimation can be seen in the graph of the estimated attenuation: where it differs from the surface-reference input, it does so in the direction of the corresponding brightness temperature. For example, the strong reflectivities in the first ten kilometers to the left produce relatively light rain estimates because of the low brightness temperature, whereas the comparable reflectivities in the "convective" region produce substantially larger rain rates, since the brightness temperature is significantly higher.

To simulate the combined algorithm over land (where the passive measurements are essentially ig- 


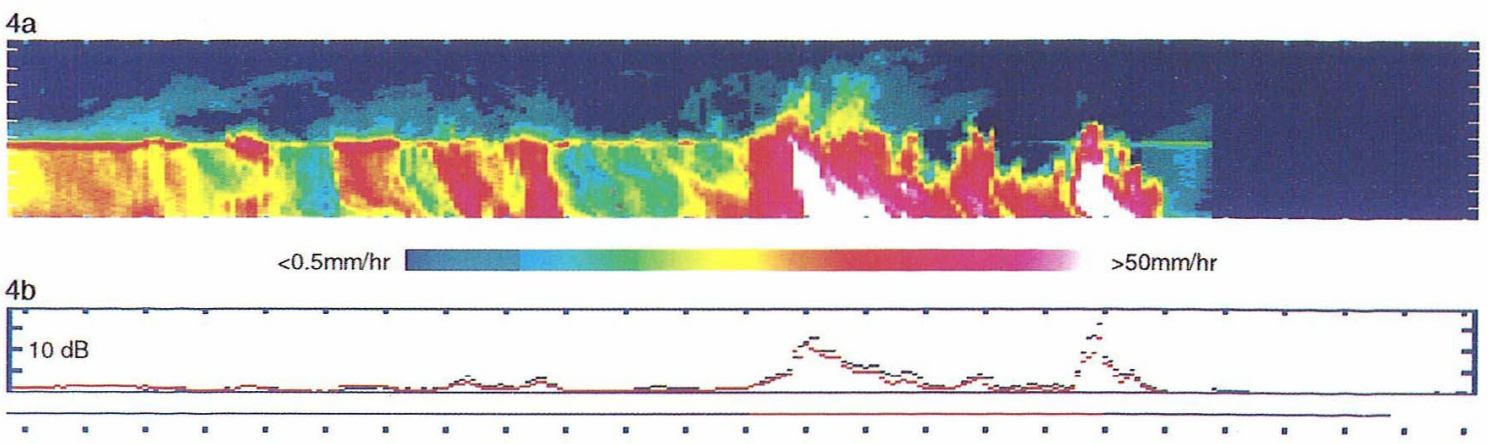

Fig. 4. Radar-only estimate of the rain field corresponding to the data of Fig. 2: (a) the rain rate (in dBR); (b) graphs of the radar-surface-reference-derived one-way attenuation (blue), of the algorithm-estimated one way attenuation (red), and of the ad hoc convective(red)/stratiform(blue) classification - the vertical tick marks are spaced $5 \mathrm{~dB}$ apart.

nored), the data were also processed through a second modified version of the algorithm, one which ignores the measured radiances but otherwise proceeds as described above. Figure 4 shows the estimates of the adapted 'no-radiances' algorithm. In this case, the algorithm's estimates of the attenuation are very close to the surface-reference inputs, as expected. For example, the strong reflectivities to the left produce larger rain estimates than those of the combined algorithm, because the low radiances are no longer taken into account. Similarly, the estimates in the convective region are relatively lower since the high radiances that boosted them for the combined algorithm are this time ignored. Note that this modified algorithm is still quite different from the TRMM radar-only algorithm: the underlying physical model is the same, but while the algorithms described in this paper are fundamentally stochastic, the TRMM radar-only algorithm follows a deterministic approach. When adjustments have to be made, it makes sharp corrections to the variables involved, whereas the Bayesian approach conditions their probability "weights" according to the required adjustment and its importance relative to the other constraints.

\section{Validation Procedure}

Aside from the obligatory comparisons with ground data to validate the near-surface estimates of the day-1 combined algorithm, four "internal" comparisons with other TRMM algorithms must be performed systematically. The first is a comparison of the r.m.s. uncertainty of the combined algorithm's rain-rate with the r.m.s. uncertainty of the TRMM radar-only inversion: an increase (or inconclusive decrease) of the uncertainty in the combined estimate would indicate that the radar and radiometer models are not sufficiently consistent with one another to explain the observations from the two instruments. Separate statistics for the convective cases are particularly relevant, since this was the main case considered in the derivation of the radiometer and radar models. The second comparison is between the integrated attenuation estimates: any bias between the combined algorithm's estimate and the one obtained from the radar measurements alone using the "surface reference technique" would indicate a possibly systematic change in the reflectivity of a rain-modified surface. The third comparison consists of a compilation of separate statistics of the DSD shape parameter $D^{\prime \prime}$, depending on the radar-only or radiometer-only classification of the rain type as stratiform or convective: since a significant difference in the statistics of $D^{\prime \prime}$ between the two classes has been observed in the Darwin and TOGA-COARE data, similar differences would be expected in the TRMM estimates. Finally, the instantaneous near-surface rain-rates estimated by the TRMM radar-only and radiometer-only algorithms, say $R_{p r}$ and $R_{t m i}$ respectively, must fall in one of two mutually exclusive cases: $R_{p r}<R_{t m i}$ or $R_{t m i}<R_{p r}$; in either case, a systematic failure of the estimate of the combined algorithm to fall between the two would indicate an error in this particular application of the Bayesian model to condition radar-only probabilities on the radiometer observations.

\section{Acknowledgements}

We wish to thank Hiroshi Kumagai and Jim Weinman for many fruitful discussions. This work was performed at the Jet Propulsion Laboratory, California Institute of Technology, under contract with the National Aeronautics and Space Administration.

\section{References}

Durden, S.L., Z.S. Haddad, E. Im, A. Kitiyakara, F.K. Li, A.B. Tanner and W.J. Wilson, 1994: Measurement of rainfall path attenuation near nadir: a comparison of radar and radiometer methods at $13.8 \mathrm{GHz}$, Radio Science, 30, 943-947. 
Haddad, Z.S., D.A. Short, S.L. Durden, E. Im, S. Hensley, M.B. Grable and R.A. Black, 1997: A new parametrization of the rain drop size distribution I.E.E.E. Trans. Geosci. and Remote Sensing, 35, $532-539$.

Hitschfeld, W. and J. Bordan, 1954: Errors inherent in the radar measurements of rainfall at attenuating wavelengths, J. Meteor., 11, 58-67.

Kawanishi, T., H. Takamatsu, T. Kozu, K. Okamoto and H. Kumagai, 1993: TRMM precipitation radar, Preprints IGARSS '93, 423-425.

Kumagai, H., R. Meneghini and K. Nakamura, 1993: Combined analysis of airborne single-frequency radar and multi-frequency radiometer observations in the TRMM-1 experiment", Proc. $26^{\text {th }}$ Intl. Conf. Radar Meteor., 696-698.

Kummerow, C., B. Barkstrom, W. Barnes, H. Christian, K. Okamoto and J. Shiue, 1997: The TRMM instrument package, Bull. Amer. Meteor. Soc.

Marzoug, M., and P. Amayenc, 1991: Improved range- profiling algorithm of rainfall rate from a space-borne radar with path-integrated attenuation constraint, I.E.E.E. Trans. Geosci. Rem. Sens., 29, 584-592.

Simpson, J., R.F. Adler, and G. North, 1988: A proposed Tropical Rainfall Measuring Mission (TRMM) satellite, Bull. Amer. Meteor. Soc., 69, 278-295.

Smith, E.A., F.J. Turk, M.R. Farrar, A. Mugnai and X.W. Xiang, 1997: Estimating $13.8 \mathrm{GHz}$ path integrated attenuation from $10.7 \mathrm{GHz}$ brightness temperatures for TRMM Combined PR-TMI precipitation algorithm J. Appl. Meteor. (accepted)

Ulbrich, C.W., 1983: Natural variations in the analytical form of the raindrop size distribution, on computer simulations of dual-measurement radar methods $J$. Climate. Appl. Meteor., 22, 1764-1775.

Weinman, J.A., R. Meneghini and K. Nakamura, 1990: Retrieval of precipitation profiles from airborne radar and passive radiometer measurements - comparison with dual-frequency radar measurements, J. Appl. Meteor., 29, 981-993. 


\title{
レーダーと放射計データを融合した熱帯降雨観測衛星(TRMM) 打上げ時用 降雨鉛直分布推定アルゴリズム
}

\author{
Ziad S. Haddad \\ （カリフォルニア工科大学ジェット推進研究所） \\ Eric A. Smith \\ (フロリダ州立大学) \\ Christian D. Kummerow \\ （NASAゴダード宇宙飛行センター） \\ Toshio Iguchi \\ （郵政省通信総合研究所） \\ Michael R. Farrar \\ (フロリダ州立大学) \\ Stephen L. Durden - Marcos Alves \\ （カリフォルニア工科大学ジェット推進研究所） \\ William S. Olson \\ （NASAゴダード宇宙飛行センター）
}

レーダーと放射計のデータを組み合わせ降雨の鉛直分布を推定する熱帯降雨観測衛星 (TRMM)の打上げ 時のアルゴリズムについて記述する。本アルゴリズムは、降雨レーダー (PR) と TRMM マイクロ波放射計 (TMI)がそれぞれ固有に持っている不確かさを考慮して作成されている。降雨推定值に大きな偏差をもた らす可能性のある特別の仮定をもうけず、なおかつ 1997 年後期の TRMM 衛星打上げ時に運用可能なよう 簡単化を図っている。本アルゴリズムでは、レーダー反射因子を使って降雨プロファイルを推定する方法 を基本としているが、その中に扔いて、レーダーデータから得られる結果が放射計から推定された善降雨 減衰量と矛盾してはならないという拘束条件を課している。このデー夕融合を行うために、解くべき問題 を粒径分布パラメータを用いて定式化している。粒径分布パラメータの事前確率密度関数 (pdf) から出発 し、ベイズ法を用いて、レーダーおよび放射計の測定值に基づいて次々と pdfに条件をつけている。こう して得られたアルゴリズムは、数学的に矛盾が無く、物理的にも妥当なものである。このアルゴリズムか ら得られる条件付き分散を使って推定值の確度を数量化することができる。分散の大きさにより、アルゴ リズムで仮定しているモデルの適切性を判断できる。 